\title{
Impact of Intraoperative Parathyroid Hormone Monitoring on the Prediction of Multiglandular Parathyroid Disease
}

\author{
Thomas Clerici, M.D., ${ }^{1}$ Michael Brandle, M.D., ${ }^{2}$ Jochen Lange, M.D., ${ }^{1}$ Gerard M. Doherty, M.D., ${ }^{3}$ \\ Paul G. Gauger, M.D. ${ }^{3}$ \\ ${ }^{1}$ Department of Surgery, Kantonsspital St. Gallen, CH-9007 St. Gallen, Switzerland \\ ${ }^{2}$ Division of Endocrinology and Diabetes, Department of Internal Medicine, Kantonsspital St. Gallen, CH-9007 St. Gallen, Switzerland \\ ${ }^{3}$ General Surgery, Division of Endocrine Surgery, University of Michigan, 48109-0331 Ann Arbor, Michigan, USA
}

Published Online: January 8, 2004

\begin{abstract}
Optimal interpretation of the results of intraoperative parathyroid hormone (IOPTH) monitoring during neck exploration for primary hyperparathyroidism (pHPT) is still controversial. The reliability of the "50\% rule" in multiglandular disease (MGD) is often disputed, mostly because of competing pathophysiologic paradigms. The aim of this study was to ascertain and corroborate the ability of IOPTH monitoring to detect MGD in a practice, combining conventional and alternative parathyroidectomy techniques. This is a retrospective single institution analysis of 69 consecutive patients undergoing cervical exploration for $\mathrm{pHPT}$ by various approaches. The IOPTH measurements were performed after induction of anesthesia but prior to skin incision and 10 minutes after excision of the first visualized enlarged parathyroid gland. In this series, 55 patients (80\%) had single adenomas, and 14 patients (20\%) had MGD. In 8 of the 14 patients with MGD, IOPTH levels were obtained sequentially after removal of every enlarged gland. Of these 8 patients, $6(75 \%)$ had a false-positive decrease (decrease below $50 \%$ of baseline value in presence of another enlarged gland) failing to predict the presence of a second enlarged gland. In 2 cases IOPTH monitoring provided a true-negative result, correctly predicting MGD. If MGD is defined by gross morphologic criteria, IOPTH monitoring fails to predict the presence of MGD reliably. However, if MGD is defined by functional criteria, the course of these patients does not seem significantly affected. The importance of these findings must be further investigated, especially with regard to the outcome of minimally invasive parathyroid procedures.
\end{abstract}

Since its introduction, intraoperative parathyroid hormone (IOPTH) monitoring has become a common adjunct to initial and reoperative surgery for primary hyperparathyroidism (pHPT) in most institutions with a large experience in endocrine surgery, especially if a minimal invasive approach is employed [1-3]. A decrease of more than $50 \%$ by 10 minutes in relation to the preoperative baseline value with a return to normal range after resection of the hyperfunctional parathyroid glands is now considered to be predictive of either postoperative biochemical cure or normocalcemia $[2,4,5]$.

Traditionally the operation for pHPT has consisted of a bilateral

Correspondence to: Thomas Clerici, M.D., e-mail: thomas.clerici@ kssg.ch neck exploration to identify all parathyroid glands. The extent of the resection was determined by the gross macroscopic changes in size, color, and consistency of the glands. IOPTH monitoring is useful to assess the adequacy of resection by functional means without the need to expose all the parathyroid glands. This can result in a reduction of operating time and costs [6]. Based on the accuracy of IOPTH monitoring and improved localization studies, especially technetium 99m sestamibi scintigraphy, several different limited access or minimally invasive techniques to excise a visualized parathyroid adenoma have since been developed [7-11].

However, there are still some concerns among endocrine surgeons about the benefits, the interpretation, and the applicability of the results of IOPTH measurements to specific clinical situations [12-14]. One of the concerns relates to the ability of IOPTHmonitoring to detect multiglandular disease (MGD) [14-16]. The frequency of MGD defined by macroscopic criteria varies from $11 \%$ to $26 \%$ [17-19]. However, the incidence of MGD was only $5 \%$ if MGD was determined to some degree by parathyroid hormone production [20].

The use of targeted operative approaches obviously does not allow the inspection of all parathyroid glands. Because an IOPTH fall of more than $50 \%$ justifies a limited inspection and therefore an abbreviated operation in relation to the conventional bilateral exploration, it can be assumed that in a substantial percentage of cases enlarged glands would be left in situ. These remaining enlarged glands might eventually hyperfunction at a later stage and therefore may have a detrimental effect on the medium-term and long-term success rate.

Recent publications indicate that there are in fact such falsepositive IOPTH monitoring results in MGD that fail to predict the presence of an additional pathologically enlarged gland $[5,14,16$, 21].

The goals of the present study were (1) to determine the frequency of false-positive and true-negative IOPTH monitoring results in the setting of pHPT with MGD and (2) to assess whether, with targeted approaches, the rate of persistent $\mathrm{pHPT}$ from a possible remaining enlarged gland is the same as with a conventional 
operation in a consecutive series of patients undergoing either standard or targeted parathyroidectomy in an endocrine surgical practice.

\section{Materials and Methods}

\section{Patients}

This is a retrospective single institutional study off 69 consecutive patients (56 women [81\%], 13 men [19\%], median age 67 years, [range: 33-87]) with pHPT who underwent conventional bilateral parathyroid exploration or videoendoscopic parathyroidectomy with IOPTH monitoring at the surgical department of the Kantonsspital St. Gallen, Switzerland, from September 1999 to December 2002. All patients had well-documented biochemical evidence of pHPT. To ascertain cure of pHPT after surgery, patients were clinically and biochemically followed after hospital discharge at 6 weeks and 6 months postoperatively. Patients with MENassociated pHPT, familial pHPT, or lithium-induced HPT were excluded from the study because of the different underlying pathogenesis and the different surgical approach $(n=11)$.

\section{Preoperative Localization Studies}

Every patient underwent a preoperative cervical ultrasound. If a mass consistent with a parathyroid adenoma could be localized sonographically and there was no evidence of relevant thyroid pathology, a technetium 99m sestamibi scintigraphy scan was performed. In case of corresponding findings in both investigations, a targeted videoendoscopic exploration was performed.

\section{Operations}

A total of 71 operations were performed on 69 patients. Two different surgical interventions were applied for primary explorations $(n=67)$ : conventional operation $(n=47)$ consisted always of a standard bilateral neck exploration with the goal of inspecting all parathyroid glands. In selected patients $(n=20)$, a targeted videoendoscopic IOPTH-controlled approach to previously localized adenomas by imaging studies was performed.

Four operations were done in patients with persistent or recurrent $\mathrm{pHPT}$. In three of these cases the pathological gland was found by cervical reexploration. In one patient a mediastinal adenoma was removed via the thoracoscopic approach.

In 25 patients partial or total thyroidectomy was added for the management of a relevant pathology of the thyroid gland (uninodular or multinodular goiter in 21, well-differentiated thyroid carcinoma in 4). All parathyroidectomies were performed by the same attending surgeon.

\section{IOPTH}

The IOPTH was measured in a peripheral blood sample of all patients after induction of anesthesia but prior to skin incision $\left(\right.$ Time $_{0}$ or $\mathrm{T}_{0}$ ) and 10 minutes after excision of the first pathologically enlarged gland or by the end of the procedure if multiple glands were excised $\left(\right.$ Time $_{1}$ or $\left.\mathrm{T}_{1}\right)$. At the beginning of our experience with IOPTH monitoring, the first measurement in recognized MGD was taken after all enlarged glands were excised. This strategy was initially chosen to minimize the number of measurements and to save costs. After the first encounter with a false-positive IOPTH result in MGD, PTH was measured sequentially 10 minutes after resection of each enlarged gland.

The measurements of intact PTH were performed with the IMMULITE Turbo Intact PTH Immunoassay (Diagnostic Products Corporation, Los Angeles, CA, USA). The predictive value of IOPTH monitoring was investigated in regard to the presence of an additional enlarged gland based on gross morphological criteria or with respect to cure, determined by normocalcemia at 6 months postoperatively. Results with a decrease in PTH levels of more than $50 \%$ from the baseline value at 10 minutes and evidence of just one pathological parathyroid gland in a bilateral neck exploration were considered to be true-positives in terms of the gross macroscopic findings $\left(\mathrm{TP}_{\text {gross }}\right)$. If IOPTH monitoring correctly predicted cure, the term $\mathrm{TP}_{\text {cure }}$ is applicable as well. The term false-positive $\left(\mathrm{FP}_{\text {gross }}\right)$ is used in the situation of a decrease of more than $50 \%$ in IOPTH monitoring in the presence of at least one additional enlarged parathyroid gland. A decrease in PTH of less than $50 \%$ in the presence of one or more enlarged glands is consistent with a true-negative $\left(\mathrm{TN}_{\mathrm{gross}}\right)$ result.

\section{Statistics}

Statistical analyses were performed using SAS Version 8.2 (SAS institute Inc., Cary, NC, USA). Data were presented as median and range. The IOPTH values and the percentage of PTH decrease were compared between the MGD group and the single adenoma group and between the single adenoma group and the targeted resection group using the Wilcoxon rank-sum test. A $p$ value $<0.05$ was considered statistically significant.

\section{Results}

In this series, 55 patients $(80 \%)$ were found to have one enlarged parathyroid gland. Two patients had persistent $\mathrm{pHPT}$ after conventional initial bilateral neck exploration with a missing inferior gland. They underwent successful reoperation after an ectopic adenoma was localized by imaging studies. One had cervical reexploration, and the other underwent thoracoscopic operation to the mediastinum.

A total of 14 patients (20\%) were found to have MGD (double adenoma 8, hyperplasia 6). All patients with MGD were explored by a conventional bilateral operation and the pathology was established by gross morphologic criteria. Follow-up examination for these patients was accomplished at 6 weeks and 6 months after the operation. All patients were biochemically cured as defined by normocalcemia at follow-up.

In the subsetting of double adenomas $(n=8)$ there were two cases of true-negative test results $\left(\mathrm{TN}_{\text {gross }}\right)$. In three patients we observed a false-positive drop in the IOPTH levels in presence of a second enlarged gland $\left(\mathrm{FP}_{\text {gross }}\right)$ (Fig. 1). In the remaining three patients PTH was measured only after both enlarged glands had been removed. With regard to cure, the results in these three cases were true-positive $\left(\mathrm{TP}_{\text {cure }}\right)$.

In primary hyperplasia $(n=6)$ three patients had false-positive results $\left(\mathrm{FP}_{\text {gross }}\right)$. In the other three patients, $\mathrm{PTH}$ was measured only after subtotal parathyroidectomy; that result was also found to be a true-positive with regard to postoperative normocalcemia $\left(\mathrm{TP}_{\text {cure }}\right)$. 


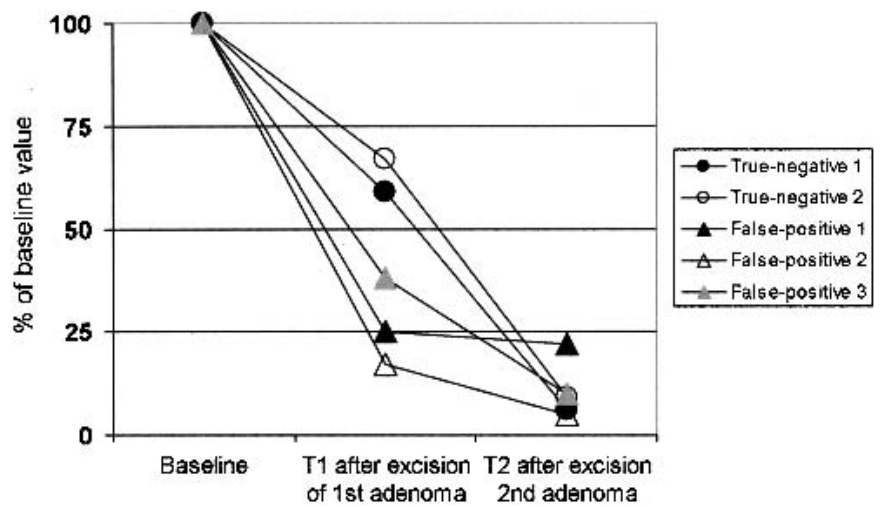

Fig. 1. Intraoperative parathyroid hormone results in patients with double adenomas and consecutively measured parathyroid hormone levels after excision of every enlarged gland.

Summing up the results in MGD $(n=14)$, we found six patients with false-positive IOPTH results $\left(\mathrm{FP}_{\text {gross }}\right)$ and two others with true-negative IOPTH results $\left(\mathrm{TN}_{\text {gross }}\right)$. In the remaining six patients with MGD, PTH was measured only after excision of the whole pathology; the result regarding cure was true-positive in all six cases $\left(\mathrm{TP}_{\text {cure }}\right)$. The IOPTH findings after excision of all enlarged glands in the patients with $\mathrm{FP}_{\text {gross }}$-and $\mathrm{TN}_{\text {gross }}$-results after excision of the first gland were also true-positive in terms of cure $\left(\mathrm{TP}_{\text {cure }}\right)$.

Overall, PTH levels were sequentially measured after excision of every enlarged gland in eight patients with MGD. In this subgroup, six patients $(75 \%)$ had a $\mathrm{FP}_{\text {gross }}$ result; the other two $(25 \%)$ had true-negative IOPTH results $\left(\mathrm{TN}_{\text {gross }}\right)$. The ability of IOPTH monitoring to rule out an additional enlarged gland (specificity) in this setting of patients with MGD was therefore $25 \%$.

The median decrease of PTH levels at $\mathrm{T}_{1}$ in the MGD group with false-positive IOPTH results ( FP $\left._{\text {gross }}\right)$ was $67.8 \%$ (Table 1 (Fig. 2). The median decrease of PTH levels at $\mathrm{T}_{1}$ in patients with a single adenoma, conventional bilateral operations, and true-positive decreases $\left(\mathrm{TP}_{\text {gross }}\right)$ was $84 \%$ and was significantly higher compared to the MGD group with $\mathrm{FP}_{\text {gross }}$ results ( $p$ value $=0.006$ ).

The median decrease of PTH levels at $\mathrm{T}_{1}$ in patients who underwent targeted videoendoscopic $(n=20)$ resection of an adenoma and who had true-positive IOPTH result regarding cure $\left(\mathrm{TP}_{\text {cure }}\right)$ was $85.8 \%$, very similar to the result in patients with a single adenoma and conventional bilateral operations ( $p$ value $>0.5)$. All patients with a targeted approach were cured as defined by normocalcemia at follow-up (median 6 months; range: 1.5 to 13 months).

In all three patients with double adenomas and a false-positive IOPTH result the second excised adenomas were considerably smaller than the first ones (Table 2). The median weight of the first one was $550 \mathrm{mg}$ as compared with the median weight of the second one at $158 \mathrm{mg}$. In the two cases with a double adenoma constellation and a true-negative decrease in the PTH level, the weights of the first adenomas were significantly greater, with weights of $11 \mathrm{~g}$ and $1.5 \mathrm{~g}$.

\section{Discussion}

Not since its introduction by F. Mandl [22], has parathyroid surgery been subjected to as much innovation and controversy as it has since the introduction of IOPTH monitoring a few years ago. We investigated the data of consecutive patients undergoing standard of targeted parathyroidectomies at our institution to address the value of IOPTH monitoring in MGD and its implications for a hybrid practice of targeted and standard parathyroidectomy techniques.

Our data have shown that using IOPTH monitoring with a cutoff threshold of $50 \%$ at 10 minutes after excision of the first visualized enlarged parathyroid gland failed to rule out multiglandular parathyroid enlargement in most of the cases where all glands could be inspected. In only two of our eight patients, IOPTH monitoring correctly indicated the presence of an additional pathologically enlarged gland.

Because targeted approaches do not allow inspection of unresected glands, it is very likely that enlarged glands remained in situ in that subgroup of our operated patients. However, this has had no apparent clinical consequence in the follow-up in regard to cure, as defined by normocalcemia.

Also, because about $15 \%$ of patients with pHPT have MGD, and a growing number of endocrine surgeons rely on IOPTH monitoring in minimally invasive targeted procedures for $\mathrm{pHPT}$, the value of IOPTH monitoring as an adjunctive intraoperative tool needs to be well defined.

Prior to the introduction of IOPTH measurement and targeted operative approaches, the intraoperative assessment of parathyroid pathology relied upon the gross macroscopic findings. The importance of a complete inspection of all parathyroid glands for a successful operation was underscored from the very beginning of parathyroid surgery by Mandl [23]. Edis et al. showed in 1977 that cure rates above $95 \%$ with minimal morbidity could be achieved by excising the macroscopically enlarged parathyroid glands only [24]. For many years, the standard operation for pHPT has been a bilateral neck exploration exposing all four glands and removing the gross macroscopic pathology. This procedure has been enormously successful, with well-documented cure-rates of about $95 \%$ in the hands of experienced endocrine surgeons.

If we assume that the removal of all enlarged parathyroid glands is essential to cure, the fact that IOPTH monitoring fails to predict the presence of residual enlarged glands would have relevance for the cure rate. Therefore the success of the operation would be at risk if the surgeon did not expose all glands and relied only on the IOPTH measurement to assess the extent of the necessary resection. Based on these considerations targeted operative techniques done without demonstrating all glands would have a detectable failure rate. Because the standard for this operation is a cure rate of approximately $95 \%$, any procedure having a lower rate because of a limited exploration and the inadequacy of IOPTH monitoring would be at least questionable.

On the other hand, we can assume that about $15 \%$ of the patients with pHPT have MGD defined by gross macroscopic criteria and about $50 \%$ of the targeted explorations in patients with MGD have residual enlarged parathyroid glands left in place based on falsepositive IOPTHresults. A decrease in the cure rate in patients with limited explorations would thus be expected. In contrast to that estimation, however, the published cure rates of authors using different minimally invasive techniques show barely any relevant failure rates at medium-term follow-up [6, 11, 25, 26] (Table 3). In fact, the reported medium-term cure rates of these authors are as excellent as the known results of conventional exploration in experienced hands. Essentially, that would mean that the same results could be achieved either by conventional exploration excising all 
Table 1. Parathyroid hormone (PTH) levels at baseline and at 10 minutes after removing first adenoma (median and range).

\begin{tabular}{|c|c|c|c|c|c|}
\hline & $\begin{array}{l}\text { Bilateral exploration- } \\
\text { single adenoma }\left(\mathrm{TP}_{\text {gross }}\right)\end{array}$ & $\begin{array}{l}\text { Targeted exploration- } \\
\text { single adenoma }\left(\mathrm{TP}_{\text {cure }}\right)\end{array}$ & $\begin{array}{l}\text { Bilateral exploration- } \\
\left.\text { MGD ( } \mathrm{FP}_{\text {gross }}\right)\end{array}$ & $\begin{array}{l}p \text { value } \mathrm{TP}_{\text {gross }} \\
\text { versus } \mathrm{FP}_{\text {gross }}\end{array}$ & $\begin{array}{l}p \text { value } \mathrm{TP}_{\text {gross }} \\
\text { versus } \mathrm{TP}_{\text {cure }}\end{array}$ \\
\hline$n$ & 31 & 20 & 6 & & \\
\hline PTH at baseline & $183(65-2370)$ & $148.5(62-440)$ & $212.5(108-1025)$ & NS & NS \\
\hline$\%$ decrease & $84 \%$ & $85.8 \%$ & $67.8 \%$ & 0.006 & NS \\
\hline
\end{tabular}

MGD: multiglandular disease; $\mathrm{TP}_{\text {gross }}$ : true-positive gross macroscopic findings; $\mathrm{FP}_{\text {gross: }}$ false-positive gross macroscopic findings; $\mathrm{TP}_{\text {cure }}$ : true-positive cure; NS: $p$ value $>0.05$.

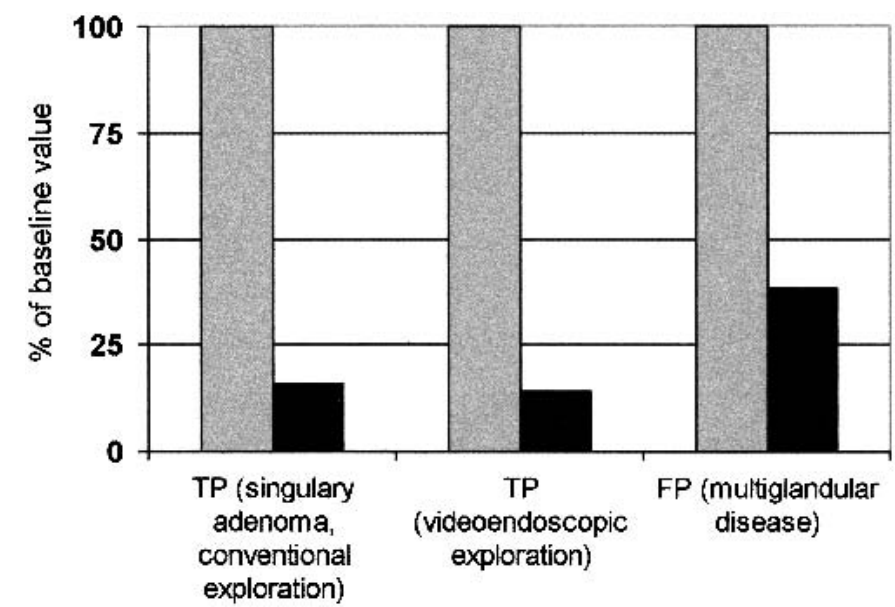

Fig. 2. Comparison of the median decrease at $\mathrm{T}_{1}$ of $\mathrm{TP}_{\text {gross }}$ (true-positive gross macroscopic findings; single adenoma and conventional exploration), $\mathrm{TP}_{\text {cure }}$ (true-positive cure; videoendoscopic exploration), and $\mathrm{FP}_{\text {gross }}$ (falsepositive gross macroscopic findings; multiglandular disease). Gray bars: baseline; black bars: $\mathrm{T}_{1}$.

Table 2. IOPTH results and weight of the adenomas in the double adenoma setting.

\begin{tabular}{lcl}
\hline & $\begin{array}{c}\text { Weight 1st } \\
\text { adenoma }(\mathrm{mg})\end{array}$ & $\begin{array}{l}\text { Weight 2nd } \\
\text { adenoma }(\mathrm{mg})\end{array}$ \\
\hline False-positive $(n=3)$ & 630 & 160 \\
& 550 & 158 \\
True-negative $(n=2)$ & $340 \mathrm{mg}$ & 110 \\
& 11,000 & Not documented \\
& 1500 & 170 \\
\hline
\end{tabular}

IOPTH: intraoperative parathyroid hormone.

parathyroid pathology on gross findings or by limited resection accompanied by a drop of more than $50 \%$ in the IOPTH monitoring. This conclusion involves accepting the fact that there would remain nonsecreting or hyposecreting enlarged parathyroid glands in some patients. The behavior of these remaining enlarged glands is crucial to the long-term success of targeted parathyroidectomy. If a nonsecreting adenoma could start autonomous PTH production weeks, months, or years after the excision of the first predominantly secreting adenoma, it would lead to a higher recurrence rate following targeted procedures. One such well-documented case has recently been reported by Zettinig et al. [27]. A 47-year-old woman had evidence of biochemical cure as defined by normocalcemia and normal iPTH levels one week after a successful minimally invasive open resection of enlarged gland in the left thyrothymic ligament. Four weeks later the patient developed hypercalcemia, followed by elevated levels of iPTH. After repeated localization studies, a second adenoma with a diameter of $10 \mathrm{~mm}$ was removed from the right thyrothymic ligament. The values for calcium and iPTH remained normal during 12 months of follow-up.

A pathophysiologic explanation for different secreting patterns of enlarged glands in a patient with MGD might be the hypothesis of different "set points" for PTH secretion in each enlarged gland. Brown et al. studied the effect of calcium concentrations on the release of PTH in dispersed parathyroid cells [28]. They found a heterogeneous responsiveness to calcium levels in different pathologic conditions. Cell cultures out of adenomas tended to have more elevated and more variable set points (calcium concentration half-maximally inhibiting PTH release) than parathyroid cells extracted from normal or hyperplastic parathyroid tissue. If after resection of the predominantly hypersecreting adenoma the calcium level would stay above the set point of the remaining enlarged gland, no excessive PTH production would occur, and therefore the remaining enlarged gland would be missed by IOPTH monitoring at the time of exploration. To achieve long-term results with targeted parathyroidectomy equivalent to the results obtained with standard bilateral exploration, it is crucial to know whether the set point of an adenoma remaining in situ might change over time and why it might do so.

The fact that the median IOPTH decrease 10 minutes after excising the first enlarged gland in the false-positive group $\left(\mathrm{FP}_{\text {gross }}, n\right.$ $=6$ ) was significantly less than in the true-positive group $\left(\mathrm{TP}_{\text {gross }}, n\right.$ $=31$ ) with a single adenoma is interesting and may be a hint that there is an additional enlarged gland (Fig. 2). Investigating these differences in respect to behavior-or rather kinetics-of IOPTH in these two groups may offer a way to better differentiate the decrease pattern of both. It might then be possible to establish rules that would be more accurate in predicting the presence of MGD than the gross $50 \%$ rule.

In our data, double adenomas were associated with $\mathrm{FP}_{\text {gross }}$ in three of the five patients. These findings are similar to other data published recently. In 1999 Gordon et al. reported four falsepositive results in 14 patients with double adenomas undergoing bilateral exploration [5]. Gauger at al. analyzed the data of $457 \mathrm{pa}-$ tients who had undergone conventional parathyroidectomy at two institutions [16]. Patients with limited exploration were excluded. Twenty patients were reported to have double adenomas, corresponding to $4.4 \%$ of the operated patients. Of those, $55 \%$ were found to have false-positive results in IOPTH monitoring. Jaskowiak et al. investigated IOPTH results in 57 consecutive patients [14]. Most of the operations were done by bilateral exploration. In four patients a double adenoma constellation was found. Two of the four patients had false-positive IOPTH results, whereas the other two had true-negative results. The cumulative experience with double adenomas of these authors is summarized in Table 4. The 
Table 3. Cure rates of targeted minimally invasive procedures for $\mathrm{pHPT}$.

\begin{tabular}{|c|c|c|c|c|}
\hline Authors & Cases & Procedure & Follow-up (months) & Cure rate \\
\hline $\begin{array}{l}\text { Prager et al. [11]; Zitinig et al. [27] and } \\
\text { Niederle, personal communication } \\
5 / 20 / 02\end{array}$ & 103 & Open minimal invasive parathroidectomy (oMIP) & $6-22$ & $98.1 \%$ \\
\hline Lorenz. et al. [26] & 123 & $\begin{array}{l}\text { Minimal invasive video-assisted parathyroidectomy } \\
\text { (MIVAP) }\end{array}$ & $3-12$ & $100 \%$ \\
\hline Udelsman [6] & 255 & Minimally invasive Parathyroidectomy (MIP) & Mean: 14 months & $99 \%$ \\
\hline
\end{tabular}

pHPT: primary hyperparathyroidism.

Table 4. Cumulative experience at four institutions with IOPTH in double adenomas.

\begin{tabular}{|c|c|c|c|c|c|}
\hline & $\begin{array}{l}\text { Fraction of } \\
\text { double adenoma }\end{array}$ & $\begin{array}{l}\text { Operative } \\
\text { exploration }\end{array}$ & $\begin{array}{l}\text { Number } \\
\text { of cases }\end{array}$ & $\begin{array}{l}\text { True-negative } \\
\text { result }\end{array}$ & $\begin{array}{l}\text { False-positive } \\
\text { result }\end{array}$ \\
\hline Gordon et al. [5] & $19.4 \%$ & Bilateral & 14 & 10 & 4 \\
\hline Gauger et al. [16] & $4.4 \%$ & Bilateral & 20 & 9 & 11 \\
\hline Own experience & $11.6 \%$ & Bilateral & 5 & 2 & 3 \\
\hline Combined results & & & 43 & $23(53.5 \%)$ & $20(46.5 \%)$ \\
\hline
\end{tabular}

specificity of IOPTH results in the combined experience for the grossly defined double adenoma setting was merely $53.5 \%$ (specificity defined as true-negative results/(true-negative results + false-positive results)).

Late parathyroid function after IOPTH guided parathyroidectomy has been studied by Carneiro and Irvin [29]. They compared the medium-term results of successful parathyroidectomy guided by IOPTH monitoring with the long-term results of successful standard bilateral neck exploration. In their study the secretory function of the remaining nonvisualized glands at 2 years after the IOPTH guided operation was not significantly different from function in the patients who had undergone bilateral neck exploration with excision of all grossly enlarged glands. However, patients with persistent disease, defined as hypercalcemia and elevated iPTH within 6 months, had been excluded to emphasize the long-term results of both operative approaches. Therefore, patients with early recurrences within the first half-year after the operation were not included and may have created a bias.

Nevertheless, the mid-term results of IOPTH-guided targeted parathyroidectomy published to date seem to indicate that the cure rates are similar to those achieved with conventional bilateral neck exploration [6, 11, 25, 26, 29]. If these results could be reproduced in true longitudinal long-term studies, they would not only further justify targeted parathyroidectomy with IOPTH monitoring, they would also correspond to a change in assumptions about parathyroid pathophysiology. Such conclusions would also suggest that the presence of a functional assessment of parathyroid normality has truly supplanted the previous gross size assessment of pathology.

\section{Conclusions}

In our study, IOPTH monitoring failed to predict the presence of residual grossly enlarged parathyroid glands in $75 \%$ of the cases, on the basis of the threshold of a mandatory decrease of at least $50 \%$ from the preoperative baseline PTH value at 10 minutes after excision of the first visualized enlarged gland. However, there is increasing evidence that there may be different secreting pattern in different parathyroid adenomas and that resection of the exclusively hypersecreting adenoma or adenomas alone could lead to cure. At this stage we may have reached a point where we must reassess our comprehension of the pathophysiology of the parathyroid glands and therefore our approach to treatment.

Résumé. L'interprétation optimale peropératoire des résultats du dosage de l'hormone parathyroïdienne (IOPTH) pendant l'exploration cervicale pour hyperparathyroïdie primitive (pHPT) reste un sujet de controverse. La fiabilité de la règle des " $50 \%$ " en ce qui concerne la maladie multiglandulaire (MGD) est souvent mise en défaut par rapport aux paradigmes physiopathologiques. Le but de cette étude a été de déterminer et de corroborer la capacité du monitorage IOPTH pour détecter la MGD dans une pratique qui combine les techniques de parathyrö̈dectomie conventionnelle et mini-invasive. Par une analyse rétrospective mono institutionnelle de 69 patients consécutifs ayant eu une exploration cervicale pour pHPT par des approches différentes, on a mesuré l'IOPTH après induction anesthésique mais avant l'incision cutanée et $\mathbf{1 0}$ minutes après excision de la première glande parathyroïde augmentée de volume. 55 patients $(80 \%)$ avaient un seul adénome et 14 patients $(20 \%)$ avaient une MGD. Chez huit des 14 patients MGD, les taux d'IOPTH ont été obtenus de façon séquentielle après l'ablation de chaque glande augmentée de volume. Six de ces huit patients $(75 \%)$ avaient une diminution faussement positive (diminution des valeurs de base inférieure à $50 \%$ en présence d'une autre glande augmentée de volume) un échec dans la prédiction de la présence d'une deuxième glande augmentée de volume. Dans deux cas, le monitorage IOPTH a montré un résultat négatif vrai prédisant correctement la MGD. Si la MGD est définie par des critères morphologiques macroscopiques, le monitorage par l'IOPTH ne prédit pas fidèlement la présence de MGD. Cependant, si la MGD est définie par des critères fonctionnels, l'évolution de ces patients ne semble pas être affectée. L'importance de ces données doit être explorée d'avantage surtout eu égard à l'évolution de la chirurgie mini-invasive pour cette pathologie.

Resumen. La optima interpretación de los resultados de la monitoria intraoperatoria de hormona paratiroidea (PTHIO) en el curso de una exploración cervical por hiperparatiroidismo primario (HPTp) todavía es motivo de controversia. La confiabilidad de la regla de " $50 \%$ " en los casos de enfermedad multiglandular (EMG) es frecuentemente disputada, generalmente en relación con competentes paradigmas fisiopatológicos. El propósito del presente estudio fue comprobar y corroborar la capacidad de la monitoría de la PTHIO en la detección de EMG en una práctica que combina técnicas de paratiroidectomía convencionales y alternativas. Es un estudio retrospectivo realizado en una sola institución sobre 69 
pacientes consecutivos sometidos a exploración cervical por HPTp por abordajes diversos. Las mediciones de PTHIO fueron realizadas luego de la inducción de la anestesia pero antes de la incisión de la piel y a los $\mathbf{1 0}$ minutos después de la resección de la primera glándula que aparecía aumentada de tamaño. 55 pacientes $(80 \%)$ tuvieron adenomas únicos y 14 20\%) EMG. En 8 de los 14 pacientes con EMG, los niveles de PTHIO fueron determinados en forma secuencial luego de la resección de cada glándula hipertrófica; 6 de estos 8 pacientes (75\%) exhibieron un descenso falso positivo (descenso mayor de $50 \%$ sobre el nivel de base en presencia de otra glándula hipertrófica) fallando así en la predicción de la presencia de una segunda glándula hipertrófica. En 2 casos la monitoría de PTHIO constituyó un resultado negativo real, con lo cual se predijo EMG. Si la EMG se define por macrocriterios morfológicos, la monitoría de PTHIO falla en la predicción confiable de la presencia de EMG. Sin embargo, si la EMG es definida por criterios funcionales, la evolución de estos pacientes no parece afectarse en forma significativa. La importancia de estos hallazgos deber ser investigada más a fondo en relación con el resultado de los procedimientos de cirugía paratiroidea mínimamente invasora.

\section{References}

1. Irvin GL, Deriso GT. A new practical intraoperative parathyroid hormone assay. Am. J. Surg. 1994;168:466-468

2. Irvin GL, Prudhomme DL, Deriso GT, et al. A new approach to parathyroidectomy. Ann. Surg. 1994;219:574-579

3. Boggs JE, Irvin GL, Molinari AS, et al. Intraoperative parathyroid hormone monitoring as an adjunct to parathyroidectomy. Surgery 1996; 120:954-958

4. Libutti SK, Alexander HR, Bartlett DL, et al. Kinetic analysis of the rapid intraoperative parathyroid hormone assay in patients during operation for hyperparathyroidism. Surgery 1999;126:1145-1150

5. Gordon LL, Snyder WH, Wians F, et al. The validity of quick intraoperative parathyroid hormone assay: an evaluation in seventy-two patients based on gross morphologic criteria. Surgery 1999;126:10301035

6. Udelsman R. Six hundred fifty-six consecutive explorations for primary hyperparathyroidism. Ann. Surg. 2002;235:665-672

7. Miccoli P, Pinchera A, Cecchini G, et al. Minimally invasive, videoassisted parathyroid surgery for primary hyperparathyroidism. J. Endocrinol. Invest. 1997;20:429-430

8. Naitoh T, Gagner M, Garcia-Ruiz A, et al. Endoscopic endocrine surgery in the neck. an initial report of endoscopic subtotal parathyroidectomy. Surg. Endosc. 1998;12:202-205

9. Gauger PG, Reeve TS, Delbridge LW. Endoscopically assisted. minimally invasive parathyroidectomy. Br. J. Surg. 1999;86:1563-1566

10. Henry JF, Defechereux T, Gramatica L, et al. Minimally invasive videoscopic parathyroidectomy by lateral approach. Langenbecks Arch. Surg. 1999;384:298-301

11. Prager G, Czerny C, Kurtaran A, et al. Minimally invasive open parathyroidectomy in an endemic goiter area: a prospective study. Arch. Surg. 2001;136:810-816

12. Starr FL, Decresce R, Prinz RA. Use of intraoperative parathyroid hormone measurement does not improve success of bilateral neck exploration for hyperparathyroidism. Arch. Surg. 2001;136:536-542
13. Miura D, Wada N, Arici C, et al. Does intraoperative quick parathyroid hormone assay improve the results of parathyroidectomy? World J. Surg. 2002;26:926-930

14. Jaskowiak NT, Sugg SL, Helke J, et al. Pitfalls of intraoperative quick parathyroid hormone monitoring and gamma probe localization in surgery for primary hyperparathyroidism. Arch. Surg. 2002;137:659-668

15. Proye CA, Goropoulos A, Franz C, et al. Usefulness and limits of quick intraoperative measurements of intact (1-84) parathyroid hormone in the surgical management of hyperparathyroidism: sequential measurements in patients with multiglandular disease. Surgery 1991;110:10351042

16. Gauger PG, Agarwal G, England BG, et al. Intraoperative parathyroid hormone monitoring fails to detect double parathyroid adenomas: a 2-institution experience. Surgery 2001;130:1005-1010

17. Proye CA, Quievreux JL, Gontier A, et al. Multi-glandular lesions in primary hyperparathyroidism. late outcome of 86 consecutive patients treated with conservative surgery. Chirurgie 1989;115:723-732

18. van Heerden JA, Grant CS. Surgical treatment of primary hyperparathyroidism: an institutional perspective. World J. Surg. 1991;15:688692

19. Bonjer HJ, Bruining HA, Birkenhager JC, et al. Single and multigland disease in primary hyperparathyroidism: clinical follow-up, histopathology, and flow cytometric DNA analysis. World J. Surg. 1992;16: 737-743

20. Molinari AS, Irvin GL, Deriso GT, et al. Incidence of multiglandular disease in primary hyperparathyroidism determined by parathyroid hormone secretion. Surgery 1996;120:934-936

21. Garner SC, Leight GS. Initial experience with intraoperative PTH determinations in the surgical management of 130 consecutive cases of primary hyperparathyroidism. Surgery 1999;126:1132-1137

22. Mandl F. Therapeutischer Versuch bei einem Falle von Osteitis fibrosa generalisata mittels Exstirpation eines Epithelkörperchentumors. Zbl. Chir. 1926;5:260

23. Mandl F. Zur Technik die Parathyreoidectomie bei Osteitis fibrosa aufgrund neuerer Beobachtungen. Dtsch. Z. Chir. 1933;240:362

24. Edis AJ, Beahrs OH, van Heerden JA, et al. Conservative" versus "liberal" approach to parathyroid neck exploration. Surgery 1977;82:466473

25. Henry JF, Iacobone M, Mirallie E, et al. Indications and results of video-assisted parathyroidectomy by a lateral approach in patients with primary hyperparathyroidism. Surgery 2001;130:999-1004

26. Lorenz K, Miccoli P, Monchik JM, et al. Minimally invasive videoassisted parathyroidectomy. multiinstitutional study. World J. Surg. 2001;25:704-707

27. Zettinig G, Kurtaran A, Prager G, et al. Suppressed" double adenoma-a rare pitfall in minimally invasive parathyroidectomy. Horm. Res. 2002;57:57-60

28. Brown EM, Gardner DG, Brennan MF, et al. Calcium-regulated parathyroid hormone release in primary hyperparathyroidism: studies in vitro with dispersed parathyroid cells. Am. J. Med. 1979;66:923-931

29. Carneiro DM, Irvin GL. Late parathyroid function after successful parathyroidectomy guided by intraoperative hormone assay (QPTH) compared with the standard bilateral neck exploration. Surgery 2000; 128:925-929 